\title{
Application of the criterial approach for the choice of forming technology for rod fasteners
}

\author{
Oleg Zhelezkov ${ }^{1, *}$, Sergey Malakanov ${ }^{1}$, and Timur Galiahmetov ${ }^{1}$ \\ ${ }^{1}$ Department of Mechanics, Nosov Magnitogorsk State Technical University , 455000, Lenin Avenue \\ 38, Magnitogorsk, Russia
}

\begin{abstract}
The article presents the results of the application of the developed complex criterial approach for evaluating the production processes of fasteners such as bolts with hexagon head. An estimation of two technologies for manufacturing bolts was made, based on the criterial evaluation, the most rational production variance was selected.
\end{abstract}

Developing multi-operation processes for forging details of complex shape, it is necessary to take into account a large number of factors affecting the efficiency of processes and the quality of products. The calculations used do not always allow to determine with high accuracy and reliability rational parameters and deformation regimes, which leads to the need for experimental forging and technology adjustments. At the same time, the search for rational technology largely depends on the experience and intuition of the designertechnologist. It should be noted that the results of calculations of individual parameters of deformation processes (deformation force, stress-strain state parameters, plasticity resource, etc.) do not allow to comprehensively evaluate the efficiency of the technologies being developed as a whole.

A technique was proposed for the search for a rational technology for manufacturing complex-shaped articles using multi-operation processes of plastic deformation on the basis of a complex criterial approach [1]. Further development of the technique is reflected in article [2]. According to the developed method, several variants of possible technology with different regimes and form-change at the individual transitions are first determined. Then, using modern methods of full-scale and computer modeling of forging processes, the main parameters (stress-strain state, energy-force parameters, stability parameters of the stamped billet, plasticity resource, product quality, etc.) are determined for each technology variant. For each parameter, its criteria is defined:

$$
K=\frac{P_{i}}{P_{\max }}
$$

where $P_{i}$ - parameter for the $i$-th version of the technology; $P_{\max }$ - parameter for the technology variant, which it takes the greatest value.

*Corresponding author: samalakanov@mail.ru 
The criteria are summarized for each technology and the technology is used as the basis for which the summary criteria has a minimum value.

When searching for a rational technology for manufacturing rod fasteners with hexagon head using a complex criterial approach, two variants of the technological process were considered:

- cold forging of the barrel head and cutting on the hexagon (variant No.1, see Fig. 1);

- cold forging of a cylindrical head and unbroken pressing of a hexagon with extrusion of a recess (variant No.2, see Fig. 2).
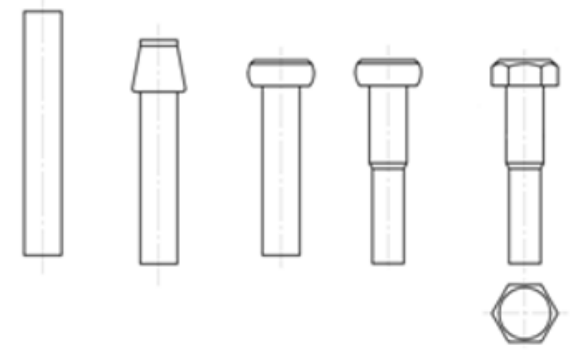

Fig. 1. Cold forging of the barrel head and cutting on the hexagon.
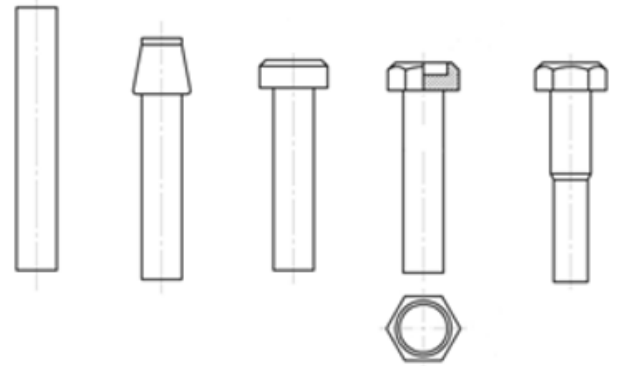

Fig. 2. Cold forging of a cylindrical head and unbroken pressing of a hexagon with extrusion of a recess.

In this paper, the evaluation was performed using the longitudinal stability criteria, the power criteria, the energy criteria, the tool wear criteria, the fracture criteria, and the metal consumption criteria.

In the manufacture of bolts and screws, the stability of the landing process depends on the size of the stamped portion of the workpiece. To evaluate the possibility of the deformation process is used parameter, which is called the coefficient of forging:

$$
k_{B}=l_{0} / d_{0},
$$

where $l_{0}$ - the length of the deformable part of workpiece, $\mathrm{mm} ; d_{0}$ - the diameter of the workpiece, $\mathrm{mm}$.

The smaller the value of $k_{B}$, the more stable the deformation process proceeds and the probability of longitudinal bending decreases. With a large value of $k_{B}$, a loss of stability, i.e., longitudinal bending of the stamped portion of the rod, is possible, which leads to the appearance of a defective workpiece.

On the basis of numerous theoretical and experimental studies, as well as practical experience, it is established that when forging for one transition the landing factor $k_{B}$ should not exceed 2.3 [3]. If $k_{B} \geq 2,3$, then forging the head must be done in several 
transitions. It should be noted that when stamping bolts it is necessary to ensure a highquality clean cut of the workpiece and perpendicularity of the cutting plane to the longitudinal axis [4].

It should be noted that the possibility of bending the workpiece with draft increases with decreasing frictional forces along the contacting surfaces of the workpiece and punch. Therefore, under unfavorable conditions, to avoid longitudinal bending of the workpiece, its end part is pinched in the punch. From this point of view, forging schemes using a tool with a tapered working surface are more preferable, since they provide a larger area of the contact surface during deformation.

Thus, the criteria of longitudinal stability:

$$
K_{L S}=\frac{k_{B_{i}}}{k_{B_{\max }}},
$$

where $k_{B_{i}}$ - the forging coefficient for the $i$-th technology; $k_{B_{\max }}$ - the coefficient of forging by technology, which it takes the maximum value.

With the development of new processes of forging and construction equipment, with the expansion of the field of application of metal forming, with the improvement of the quality of the raw material and processing speeds, the issue of the required effort, the work of deformation and power becomes more and more important. The determination of these values is necessary in the transition to the manufacture of new products, for example, products with new shapes and technological parameters of forging, to select the source material or to address issues of improving the productivity of equipment. The effective capacity of the equipment is limited, on the one hand, by the maximum permissible deformation force, and on the other hand, by the overload capacity of the motor. Only with simultaneous consideration of efforts and effective power can the most efficient and full use of forging equipment, without fear of overloading.

When developing the process should pick up such methods in which the desired shape of the product would be obtained by the simplest way, with the least effort and energy.

Using the results of computer and full-scale modeling, for each variant of the technology, the maximum deformation forces were determined and the force criteria $K_{F}$ :

$$
K_{F}=\frac{F_{i}}{F_{\max }},
$$

where $F_{i}$ - the maximum forging force for the $i$-th technology variant, $\mathrm{N} ; F_{\max }-$ the maximum forging force for the technology variant, which it takes the highest value, $\mathrm{N}$.

When the energy criteria is found, a diagram $F=f(z)$ of the dependence of the deformation force $F$ on the movement of the tool $z$ is constructed for each technology variant on the basis of either computer simulation or experimental data. A typical curve is shown in Fig. 3. 


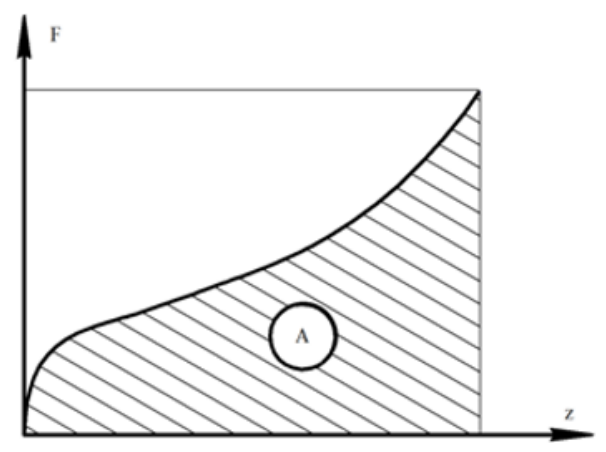

Fig. 3. Typical diagram of the dependence of the deformation force $F$ on the displacement of the punch $\mathrm{z}$.

With a high degree of accuracy, the curve $F=f(z)$ can be approximated by a polynomial of the fifth degree:

$$
F=k_{1}(z)^{5}+k_{2}(z)^{4}+k_{3}(z)^{3}+k_{4}(z)^{2}+k_{5} z
$$

Then the deformation work $A$ is determined as the area of the figure bounded by the curve $F=f(z)$ and the $z$-axis of the abscissas $z$ (Fig. 3). For this, the integral of the equation (5) is determined from 0 to $z$, where $z$ is the total stroke of the tool for the entire stage of deformation:

$$
A=\int_{0}^{z_{k}}\left[k_{1}(z)^{5}+k_{2}(z)^{4}+k_{3}(z)^{3}+k_{4}(z)^{2}+k_{5} z\right] d(z) .
$$

After integration:

$$
A=\left.\left[\frac{1}{6} k_{1}(z)^{6}+\frac{1}{5} k_{2}(z)^{5}+\frac{1}{4} k_{3}(z)^{4}+\frac{1}{3} k_{4}(z)^{3}+\frac{1}{2} k_{5}(z)^{2}\right]\right|_{0} ^{z_{k}} .
$$

The Energy Criteria:

$$
K_{E}=\frac{A_{i}}{\mathrm{~A}_{\max }}
$$

where $A_{i}$ - the work of deformation during forging according to the i-th variant of the technology, J; $A_{\max }$ - the work of deformation during forging according to the variant, which the work has the maximum value, $\mathrm{J}$.

The problems of improving the wear resistance of parts and tools from a variety of materials dedicated to the works by I. V. Kragelskiy [5], D. N. Garkunov [6] V. N. Vinogradova [7], M. M. Khrushchev [8]. The diversity of evaluation criteria of wear resistance indicates the significantly different approaches of researchers to the explanation and description of the wear mechanisms of materials.

The criteria of wear resistance of the tool is based on the energy theory of wear of solids [5,6], according to which the volume wear $\Delta W$ is proportional to the work of the friction forces $A_{F r}$ in the contact zone: 


$$
\Delta W=J_{\omega} \cdot A_{F r}
$$

where $J_{\omega}$ - index of the energy intensity of wear, which is determined on the basis of experimental studies using special equipment (friction machine), $\mathrm{m}^{3} / \mathrm{J}$.

This approach is used in assessing the wear resistance of a thread-rolling tool [9].

In general:

$$
A_{F r}=F_{F r} s=\mu F_{N} s
$$

where $F_{F r}$ - the friction force, $\mathrm{N} ; \mu$-coefficient of friction; $F_{N}$ - force of normal pressure, $\mathrm{N} ; s$ - movement, $\mathrm{m}$.

The criteria of tool wear:

$$
K_{T W}=\frac{A_{F r_{i}}}{A_{F r_{\max }}},
$$

where $A_{F r_{i}}$ - the work of frictional forces during forging according to the $i$-th version of the technology, $\mathrm{J} ; A_{F_{\max }}$ - work of frictional forces during forging according to a variant of technology with maximum frictional forces, $\mathrm{J}$.

In a comparative analysis of different versions of the technology of manufacturing core products, the well-known criteria for the destruction of Cockcroft and Latham [10] was used, which is determined directly in the processes of computer modeling with the use of "DEFORM-3D".

Relative criteria of destruction:

$$
K_{D}=\frac{D_{i}}{D_{\max }},
$$

where $D_{i}$ - the maximum value of the Cockroft-Latham criteria for forging in the $i$-th version of the technology; $D_{\max }$ - the maximum value of the Cockcroft-Latham criteria from the variant in which this criteria takes the highest value.

An important economic factor affecting the efficiency of the process, the manufacture of fasteners is the consumption of metal per unit of output. Metal waste appears when the front and rear ends of the rod or rupture are removed and when blanks are removed during the working-out and adjustment of the forging process, as well as in the implementation of the spent technology. For example, in the case of using the technology of variant No.1 (see Fig. 1), when the barrel head is cut into a hexagon, the cut metal is waste. And when using non-fibrous forging with the extrusion of recess (variant No.2), the metal is saved.

The criteria of metal consumption:

$$
K_{M C}=\frac{V_{i}}{V_{\max }},
$$

where $V_{i}$ - the volume of the head before the final hexahedron for the $i$-th technology, $\mathrm{m}^{3}$; $V_{\max }$ - the volume of the head before the final formation of the hexagon for the technology, according to which the volume is maximal, $\mathrm{m}^{3}$. 
For each of the technologies considered, the criteria are summarized and the technology based on which the total criteria takes the minimum value is taken as the basis.

Table 1 presents the results of a search for a rational technology for the manufacture of rod fastaners (bolts) with hexagon head.

Table 1. The results of the search for a rational technology for making bolts.

\begin{tabular}{|c|c|c|c|c|c|c|c|}
\hline Variant of technology & $K_{L S}$ & $K_{F}$ & $K_{E}$ & $K_{T W}$ & $K_{D}$ & $K_{M C}$ & $\sum K$ \\
\hline $\begin{array}{c}\text { Forging the barrel head and cutting } \\
\text { the hex head (variant No.1) }\end{array}$ & 1 & 0,89 & 0,85 & 1 & 1 & 1 & 5,74 \\
\hline $\begin{array}{c}\text { Forging of a cylindrical head and } \\
\text { forging of a hexagon with extrusion } \\
\text { of a recess (variant No.2) }\end{array}$ & 0,72 & 0,93 & 0,91 & 0,89 & 0,61 & 0,91 & 4,97 \\
\hline
\end{tabular}

As can be seen from Table 1, the best overall criteria for the technology is in variant No. 2 , in which cold forging of the hexagon head is performed with extrusion of a recess.

As a result, a technique was developed to search for rational shaping in multi-transient processes for forging core articles of complex shape on the basis of a complex criterial approach with respect to bolting technology.

\section{References}

1. O.S. Zhelezkov, S.A. Malakanov, S.O. Zhelezkov, Searching of rational forming in multijunction processes of plastic deformation on the basis of complex criteria-based approach, Forging and stamping production. Processing of materials by pressure, № 4, pp. 8-12 (2015).

2. S.A. Malakanov, O.S. Zhelezkov, T.Sh. Galiakhmetov, V.A. Arzamastseva, Criterial approach for designing technological processes of manufacture of fastaners and spring terminals (NMSTU, Magnitogorsk, 2017).

3. V.Ya. Gerasimov, O.S. Zhelezkov, V.G., Parshin, Stability of eccentrically compressed blanks of circular cross-section, Proceedings of IV conf. in mathematics and mechanics, pp. 150-151 (1974).

4. M.G. Polyakov, V.G., Parshin, V.Ya. Gerasimov Effect of cut quality on the accuracy of cold-fastened fasteners, Bul. in-ta Chermetinformation, № 3, pp. 49-50, (1974).

5. I.V. Kragelsky Friction and wear (Mechanical engineering, 1968).

6. Garkunov D.N. Tribotechnics (wear and tearlessness) (Publishing House of the MSHA", 2001).

7. V.N. Vinogradov, G.M. Sorokin, Mechanical wear of steels and alloys. ( Nedra, Moscow, 1996).

8. M.M. Khrushchov, M.A. Babichev, Abrasion wear. (Nauka, Moscow, 1970).

9. O.S. Zhelezkov, S.A. Malakanov, V.V. Semashko, Prediction of thread rolling tools wear resistance. Procedia Engineering. "International Conference on Industrial Engineering, ICIE 2017", pp. 630-635 (2017).

10. M.G. Cockcroft, D.J. Latham, Ductility and Workability of Metals, Journal of the Institute of Metals, v. 96, p. 33-36 (1968). 